\title{
Synthesis of pyridine and methylpyridines over zeolite catalysts
}

\author{
Nellya Gennadievna Grigor'eva • \\ Nadezhda Alexandrovna Filippova • \\ Marina Ivanovna Tselyutina - Boris Ivanovich Kutepov
}

Received: 4 September 2014/ Accepted: 17 November 2014/Published online: 3 December 2014

(C) The Author(s) 2014. This article is published with open access at Springerlink.com

\begin{abstract}
The synthesis of pyridines has been performed by a multi-component reaction of ethanol, formaldehyde, and ammonia in the presence of H-Beta, H-ZSM-12, and H-ZSM-5 zeolite catalysts. The maximum activity in the reaction is revealed by H-Beta zeolite; the conversion of ethanol induced by it reached $70 \%\left(400{ }^{\circ} \mathrm{C}, 2 \mathrm{~h}^{-1}\right)$. The main products of the reaction in the presence of H-Beta and H-ZSM-5 zeolites are pyridine and picolines; on H-ZSM12 picolines and lutidines. Thus, the results of the studying the effect of reaction parameters are showed that the yield of lutidine and heavy products increases with the increase of the temperature (from 200 to $400{ }^{\circ} \mathrm{C}$ ) and the decrease of the weight hourly space velocity (from 10 to $2 \mathrm{~h}^{-1}$ ).
\end{abstract}

Keywords Pyridine $\cdot$ Picolines $\cdot$ Lutidines - Zeolites · Multi-component reaction

\section{Introduction}

Pyridine and substituted pyridines are the important intermediates for the synthesis of pharmaceuticals, herbicides, metal corrosion inhibitors, rubber vulcanization accelerators, and conventional ligands for the chemical assembly of coordination compounds [1-4].

The first industrial method for the pyridine production is the separation from the coal-tar [5] where the content of it is less than $0.01 \%$.

\section{N. G. Grigor'eva $(\square) \cdot$ N. A. Filippova ·}

M. I. Tselyutina · B. I. Kutepov

Federal State Budget Institution of Science, Institute of Petrochemistry and Catalysis Russian Academy of Sciences, 141 prosp. Oktyabrya, 450075 Ufa, Russian Federation

e-mail:ngg-ink@mail.ru
To date the major industrial processes for the synthesis of pyridine and methylpyridines use gas phase condensation of carbonyl compounds with ammonia induced by the alumosilicates promoted with metals, namely, $\mathrm{Ni}, \mathrm{Cr}, \mathrm{Cd}$, $\mathrm{Zn}$, Th. The pyridine yield amounts $40-60 \%$, and a sizeable amount of by-products is formed [3, 6].

The successful application of zeolite catalysts in the processes of acid-base catalysis such as isomerization, amination, aromatics transalkylation, oligomerization, catalytic cracking, and others has opened up the new possibilities for the synthesis of N-heterocyclic compounds.

The synthesis of pyridine and alkylpyridines by a reaction of aldehydes and ketones with ammonia over MOR, FAU, BEA zeolites [7-10] and ZSM-5 zeolite modified by various metal ions [11-18] is described.

It has been determined [19-21] that the pore size HA, HX, HY zeolites had insignificantly effect on selectivity towards pyridine formation. At the same time, the H-ZSM5 zeolite and silicalite $\left(\mathrm{SiO}_{2} / \mathrm{Al}_{2} \mathrm{O}_{3}=30-120\right)$ promoted by $\mathrm{Pt}(\mathrm{II}), \mathrm{Ti}(\mathrm{I}), \mathrm{Zn}$ (II) or Co (II), have the pore diameter are nearly identical to pyridine molecule and it allows to achieve high selectivity of pyridine.

Liu et al. [22] reported that the yield of pyridine was achieved $50 \%$ using Co-ZSM-5 zeolite catalyst.

Kulkarni and Subrahmanyam [23] described the synthesis of pyridines from acetone, formaldehyde and methanol with ammonia over ZSM-5 $\left(\mathrm{SiO}_{2} / \mathrm{Al}_{2} \mathrm{O}_{3}=30,150\right.$, 280) zeolite promoted by $\mathrm{Pb}, \mathrm{W}$. The main reaction products are 2-picoline (30-47 \%) and 2,6-lutidine (15-35\%).

Van der Gaag et al. [24] proposed a method for the synthesis of pyridines from ethanol and ammonia in the presence of oxygen over ZSM- 5 zeolite promoted by Cd, $\mathrm{Co}$ or $\mathrm{Fe}$ and $\mathrm{H}-\mathrm{Mor}, \mathrm{H}-\mathrm{Y}$ zeolites. It is shown that with the increasing of the $\mathrm{SiO}_{2} / \mathrm{Al}_{2} \mathrm{O}_{3}$ ratios (from 12 to 130 ) the selectivity of pyridine increases and amount to $23-47 \%$. 
Ferrum-modified ZSM-5 zeolite showed high activity and selectivity to pyridine. In the case of using H-Mor or H-Y zeolite carbon dioxide and ethylene are major products.

Synthesis of pyridines from ethanol, formaldehyde and ammonia has been a subject of great interest [25]. This reaction was carried out for the first time by Indian scientists over various ZSM-5 catalysts. Zeolite catalysts of the other framework were not studied in this reaction.

In this paper, the multi-component reaction of ethanol with formaldehyde and ammonia under the action of different zeolite catalysts, such as H-Beta (BEA), H-ZSM-12 (MTW), H-ZSM-5 (MFI) was carried out.

\section{Experimental}

Reagents and catalysts

The ethanol (95\%), aqueous solutions of formaldehyde (37\%) and ammonia (28\%) was used with no additional purification.

The Beta zeolite (the $\mathrm{SiO}_{2} / \mathrm{Al}_{2} \mathrm{O}_{3}$ molar ratio of 18) and ZSM-12 zeolite $\left(\mathrm{SiO}_{2} / \mathrm{Al}_{2} \mathrm{O}_{3}=34\right)$ were supplied by OJSC "Angarsk Plant of Catalysts and Organic Synthesis" in $\mathrm{NH}_{4}$-form. Zeolite samples were converted into the $\mathrm{H}$-form by calcining them in the atmosphere of air at the temperature of $540{ }^{\circ} \mathrm{C}$ for $3 \mathrm{~h}$.

H-ZSM-5 $\left(\mathrm{SiO}_{2} / \mathrm{Al}_{2} \mathrm{O}_{3}=30\right)$ zeolite was obtained from OJSC "Novosibirsk Plant of Chemical Concentrates".

The zeolite samples were calcined in the atmosphere of air for $3-4 \mathrm{~h}$ at $540{ }^{\circ} \mathrm{C}$.

The catalysts were characterized by the X-Ray Phase (XRP) and X-Ray Diffraction (XRD). Studies, the Low Temperature Nitrogen Adsorption, and the Temperature Programmed Desorption of ammonia (TPD $\mathrm{NH}_{3}$ ) were described in [26-29].

General procedure for synthesis of pyridines

The reaction of ethanol with formaldehyde and ammonia was conducted in a tubular, down-flow Pyrex reactor with $20 \mathrm{~mm}$ internal diameter at the temperature of $200-400{ }^{\circ} \mathrm{C}$ and the weight hourly space velocity (WHSV) within the range of $0.5-10 \mathrm{~h}^{-1}$. The molar ratio of ethanol/formaldehyde/ammonia varies within the range of $1.0 /$ $0.4-1.1 / 1.5$. The amount of the catalysts taken for every reaction was $0.4 \mathrm{~g}$. The reaction mixture was fed from the top using a micro-pump. The product was collected at the bottom and cooled using ice-cold water.

The reaction products were analyzed by means of the gas-liquid chromatography technique using the chromatograph with the flame ionization detector (SE-30 phase, the glass capillary column of $25 \mathrm{~m}$ length; the temperature of analysis $50-280{ }^{\circ} \mathrm{C}$; the programmed heating gradient of $8{ }^{\circ} \mathrm{C} / \mathrm{min}$; the detector temperature of $250{ }^{\circ} \mathrm{C}$; the evaporator temperature of $300{ }^{\circ} \mathrm{C}$; the flow rate of the helium carrier gas of $30 \mathrm{~cm}^{3} / \mathrm{min}$ ).

High resolution mass spectra are recorded using the Fisons company instrument, its chromatograph being equipped with the $50 \mathrm{~m}$ DB-560 capillary quartz column $(50 \mathrm{~m})$.

The products were identified by comparing the mass spectra and chromatographic behavior of the separated and reference products (pyridine, picolines, and lutidines).

\section{Result and discussion}

According to the XRP, XRD data, and the adsorption measurements, all the zeolite samples tested have the crystallinity degree close to $100 \%$.

The zeolites investigated in this work belong to different structural types, namely, BEA, MTW, MFI and are differing in the crystal structure, the framework atom ratio, and acidic properties.

H-Beta zeolite has possessed the most wide rectilinear channels, bordered by the 12-ring [30]; the diameter of ZSM5 and ZSM-12 zeolite channels were the most tight ones.

Since the catalytically active centers in zeolites are basically located inside the channels, the active sites of H-Beta zeolite possessing the most open crystalline structure with the widest pores will be obviously more accessible to the reactive molecules.

In the acidic spectra of zeolite catalysts obtained by the TPD $\mathrm{NH}_{3}$ method, there are two peaks characterizing the "weak" acid sites with the temperature maximum $T_{\max }$ in the temperature range of $100-350{ }^{\circ} \mathrm{C}$ and the "strong" acid sites with the temperature maximum $T_{\max }$ in the temperature range over $350{ }^{\circ} \mathrm{C}$ (see Table 1).

The total acidity of the zeolites followed the order: H-Beta $>$ H-ZSM-5 > H-ZSM-12, as given in Table 1 . Chemical transformations on zeolites occur primarily with the acid sites; their concentration decreases in the following series: H-Beta > H-ZSM-5 > H-ZSM-12. The strength of the "strong" acid sites in the zeolite studied was evaluated by the shift of the high temperature maximum $T_{\mathrm{II}}$ in the thermal desorption patterns appeared to be approximately the same.

We have found that under the action of H-Beta, H-ZSM5, and H-ZSM-12 zeolite catalysts ethanol interacts with formaldehyde and ammonia yielding pyridine, picolines (2methylpyridine, 3-methylpyridine, 4-methylpyridine), lutidines (dimethyl-pyridines), and more "heavy" compounds as compared to dimethylpyridines (see Scheme 1).

The activity of catalysts evaluated by the degree of ethanol conversion reaches its maximum on the H-Beta 
Table 1 The characteristics of zeolite catalysts

\begin{tabular}{|c|c|c|c|c|c|c|c|c|c|c|}
\hline \multirow[t]{3}{*}{ Catalyst } & \multirow[t]{3}{*}{ Structure } & \multirow[t]{3}{*}{ Channels diameter $(\AA)$} & \multirow[t]{3}{*}{$\mathrm{Si} / \mathrm{Al}$ ratio } & \multirow[t]{3}{*}{ Degree of crystallinity (\%) } & \multicolumn{2}{|c|}{$\begin{array}{l}\text { Equilibrium } \\
\text { adsorption } \\
\text { capacity* }\end{array}$} & \multicolumn{4}{|c|}{ Acidic properties } \\
\hline & & & & & \multirow[t]{2}{*}{$\mathrm{H}_{2} \mathrm{O}$} & \multirow[t]{2}{*}{$\mathrm{C}_{6} \mathrm{H}_{6}$} & \multicolumn{2}{|c|}{$\begin{array}{l}T_{\max } \\
\left({ }^{\circ} \mathrm{C}\right)\end{array}$} & \multicolumn{2}{|c|}{$\begin{array}{l}\text { Concentration of the } \\
\text { acid sites }\left(\mathrm{mmol} \mathrm{g} \mathrm{g}^{-1}\right.\end{array}$} \\
\hline & & & & & & & I & II & $\mathrm{C}_{\mathrm{I}}$ & $\mathrm{C}_{\mathrm{II}}$ \\
\hline H-Beta & 12-Rings & $6.6 \times 6.7$ and $5.6 \times 5.6$ & 18 & 100 & 0.12 & 0.32 & 280 & 450 & 520 & 310 \\
\hline H-ZSM-12 & 12-Rings & $5.6 \times 6.0$ & 34 & 100 & 0.07 & 0.23 & 300 & 450 & 220 & 90 \\
\hline H-ZSM-5 & 10-Rings & $5.1 \times 5.5$ and $5.3 \times 5.6$ & 28 & 100 & 0.05 & 0.20 & 250 & 450 & 210 & 280 \\
\hline
\end{tabular}

$\mathrm{C}_{\mathrm{I}}$ and $\mathrm{C}_{\mathrm{II}}$ denote the concentration of $\ll$ weak $\gg, \ll$ strong $\gg$ acid sites

$* 20{ }^{\circ} \mathrm{C}$ and $\mathrm{P} / \mathrm{Ps}=0.8$

Scheme 1 Synthesis of pyridines

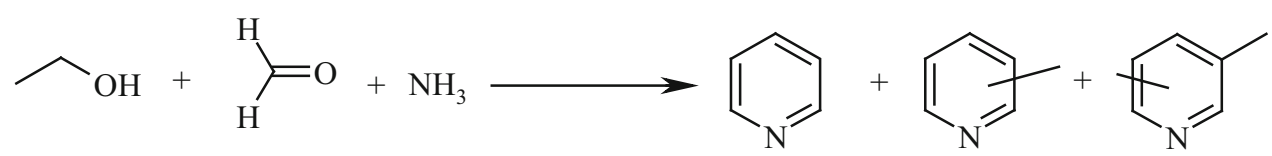

zeolite catalyst and decreases going to pentasil-zeolites $(\mathrm{H}-$ ZSM-5 and H-ZSM-12) (see Table 2).

Main reaction products in the presence of H-Beta zeolite are pyridine and methylpyridines formed in the approximately equal quantities, i.e., 44 and $46 \%$. The content of dimethylpyridines and "heavy" products is negligible - 6 and $4 \%$ (see Table 2). So far as the selectivity of the pyridine formation is concerned, close results are obtained on H-ZSM-5 zeolite: the pyridine/picoline ratio of $\approx 1 / 1$; the content of lutidines is for practical purposes, the same as on the H-Beta catalyst. It is worth to mention the higher selectivity of the "heavy-products" formation as compared to H-Beta zeolite. A distinction of the H-ZSM-12 zeolite catalyst is the higher content of methyl- and dimethylpyridines in the reaction products amounting about $77 \%$ of the pyridine total. The pyridine/picolines/lutidines ratio is 1:2.5:0.9.

Among the picolines obtained on H-ZSM-5, H-ZSM-12, and H-Beta zeolites prevails 3-methylpyridine (see Table 2). In the lutidine composition, 3,5-dimethylpyridine is the major isomer, its quantity exceeding $90 \%$.

To explain the results obtained let us refer to the characteristics of the porous structure of zeolite catalysts and their acidic properties (see Table 1).
The comparison of acidic properties and characteristics of the porous structure of the studied zeolites with their activity in the reaction of ethanol with formaldehyde and ammonia shows that the higher activity of $\mathrm{H}$-Beta zeolite as compared to H-ZSM-5 and H-ZSM-12 pentasils is defined both by the easier accessibility of the acid sites to the reactive molecules and by the higher concentration of the acid sites.

The selectivity of the pyridine formation is probably defined to the most extent by the structural characteristics of zeolite catalysts. Therefore, on the H-Beta zeolite possessing the widest channels in the series of the catalysts studied all three methylpyridine isomers are formed in sizeable quantities, whereas on the more narrow-porous H-ZSM-5 and H-ZSM-12 zeolites 3-methylpyridine is predominantly formed. The effect of the same factor (the smaller pore diameter) may be also attributed to the fact that the content of dimethylpyridines is higher on the products obtained on H-ZSM-5 and H-ZSM-12 zeolite catalysts. The bulky lutidine molecules are likely to be formed not in the zeolite channels, but on the superficial acid sites.

In the presence of the most active zeolite catalysts, the H-Beta catalyst, we studied the effect of the reaction

Table 2 Effect of the zeolite framework types on the conversion of ethanol $(\mathrm{K})$ and on the selectivity of the pyridines formation $\left(300{ }^{\circ} \mathrm{C}, 7 \mathrm{~h}^{-1}\right.$, $\mathrm{C}_{2} \mathrm{H}_{5} \mathrm{OH} / \mathrm{CH}_{2} \mathrm{O} / \mathrm{NH}_{3}$ molar ratio of $1.0 / 0.8 / 1.5$ )

\begin{tabular}{|c|c|c|c|c|c|c|c|}
\hline \multirow[t]{2}{*}{ Catalyst } & \multirow[t]{2}{*}{$\mathrm{K}(\%)$} & \multicolumn{6}{|c|}{ Selectivity (\%) } \\
\hline & & Pyridine & 2-Picoline & 3-Picolines & 4-Picolines & Lutidines & $\ll$ Heavy-products $\gg$ \\
\hline H-Beta & 40 & 44 & 9 & 22 & 15 & 6 & 4 \\
\hline H-ZSM-5 & 30 & 42 & 1 & 37 & 5 & 7 & 8 \\
\hline H-ZSM-12 & 24 & 21 & 4 & 40 & 8 & 19 & 8 \\
\hline
\end{tabular}


Table 3 The effect of temperature on the conversion of ethanol $(\mathrm{K})$ and on the selectivity of the pyridines formation $\left(\mathrm{H}-\mathrm{Beta}\right.$ catalyst, $\mathrm{C}_{2} \mathrm{H}_{5} \mathrm{OH} /$ $\mathrm{CH}_{2} \mathrm{O} / \mathrm{NH}_{3}$ molar ratio $=1.0 / 0.8 / 1.5 ;$ WHSV $=2 \mathrm{~h}^{-1}$ )

\begin{tabular}{|c|c|c|c|c|c|c|c|}
\hline \multirow[t]{2}{*}{$\mathrm{T}\left({ }^{\circ} \mathrm{C}\right)$} & \multirow[t]{2}{*}{$\mathrm{K}(\%)$} & \multicolumn{6}{|c|}{ Selectivity (\%) } \\
\hline & & Pyridine & 2-Picoline & 3-Picoline & 4-Picoline & Lutidines & $\ll$ Heavy-products $\gg$ \\
\hline 200 & 40 & 49 & 4 & 6 & 31 & 4 & 6 \\
\hline 250 & 43 & 45 & 9 & 12 & 22 & 5 & 7 \\
\hline 300 & 59 & 42 & 8 & 16 & 19 & 7 & 8 \\
\hline 350 & 66 & 39 & 3 & 32 & 5 & 11 & 10 \\
\hline 400 & 70 & 27 & 2 & 32 & 2 & 20 & 17 \\
\hline
\end{tabular}

Table 4 The effect of the WHSV on the conversion of ethanol and on the selectivity of the pyridines formation in the presence of H-Beta catalyst $\left(300{ }^{\circ} \mathrm{C} ; \mathrm{C}_{2} \mathrm{H}_{5} \mathrm{OH} / \mathrm{CH}_{2} \mathrm{O} / \mathrm{NH}_{3}\right.$ molar ratio of $\left.1.0 / 0.8 / 1.5\right)$

\begin{tabular}{llllllll}
\hline WHSV $\left(\mathrm{h}^{-1}\right)$ & $\mathrm{K}(\%)$ & \multicolumn{2}{l}{ Selectivity $(\%)$} & & \\
\cline { 3 - 7 } & & Pyridine & 2-Picoline & 3-Picoline & 4-Picoline & Lutidines & 《Heavy-products》 \\
\hline 0.5 & 63 & 38 & 5 & 16 & 18 & 12 & 10 \\
2 & 59 & 42 & 8 & 16 & 19 & 7 & 8 \\
4 & 48 & 42 & 9 & 22 & 14 & 6 & 6 \\
7 & 40 & 44 & 9 & 19 & 15 & 4 & 3 \\
10 & 36 & 49 & 10 & 22 & \\
\hline
\end{tabular}

Table 5 Effect of the reagent molar ratio on the conversion of ethanol and on the selectivity of pyridines formation in the presence of $\mathrm{H}$-Beta zeolite catalyst (at $T=300{ }^{\circ} \mathrm{C}$ and WHSV $=7 \mathrm{~h}^{-1}$ )

\begin{tabular}{|c|c|c|c|c|c|c|c|c|}
\hline \multirow[t]{2}{*}{ Feed } & \multirow[t]{2}{*}{ Molar ratio } & \multirow[t]{2}{*}{$\mathrm{K}(\%)$} & \multicolumn{6}{|c|}{ Selectivity (\%) } \\
\hline & & & Pyridine & 2-Picoline & 3-Picoline & 4-Picoline & Lutidines & $\ll$ Heavy-products $\gg$ \\
\hline \multirow[t]{4}{*}{ Ethanol-formaldehyde-ammonia } & $1.0 / 0.39 / 1.5$ & 44 & 33 & 3 & 40 & 8 & 14 & 2 \\
\hline & $1.0 / 0.53 / 1.5$ & 41 & 35 & 5 & 37 & 11 & 10 & 2 \\
\hline & $1.0 / 0.80 / 1.5$ & 40 & 44 & 9 & 22 & 15 & 6 & 4 \\
\hline & $1.0 / 1.07 / 1.5$ & 30 & 48 & 8 & 20 & 16 & 5 & 3 \\
\hline
\end{tabular}

parameters, namely, the temperature, weight hourly space velocity (WHSV), reagent molar ratio on the conversion of ethanol and on the composition of pyridines formed as a result of the interaction of ethanol with formaldehyde and ammonia.

As it follows from the data given in Table 3 the conversion of ethanol grows with the rise of temperature.

In the process, the selectivity of the pyridine formation decreases by almost half and dimethylpyridines-increases by five times. The total selectivity of the picolines formation is changed slightly-within the range of 41-36\%, while in the composition of isomers noticeable changes occur. The content of 3-methylpyridine increases with the increase of the temperature and the amount of 2- and 4-methylpyridines decreases. The content of "heavy-products" increases from $6 \%\left(200{ }^{\circ} \mathrm{C}\right)$ to $17 \%\left(400{ }^{\circ} \mathrm{C}\right)$, which is connected, apparently, with the increase in the rate of side reactions.

The influence of the WHSV on the conversion of ethanol and on the selectivity of the reaction products is depicted in Table 4.

With the increase of WHSV, the contact time between the active site and reactant molecules decreased and correspondingly the conversion of ethanol decreased from $63 \%$ at $0.5 \mathrm{~h}^{-1}$ to $36 \%$ at $10 \mathrm{~h}^{-1}$. In the process, the content of pyridine and picolines in the reaction mixture increases slightly (11 and $7 \%$, respectively) and the amount of lutidine and "heavy" products decreases.

During the studies of the effect of the reagent molar ratio of ethanol, formaldehyde and ammonia on the conversion of ethanol and the selectivity of the pyridines formation, it is indicated that with the increase of 
formaldehyde in the feed (from 0.39 to $1.07 \mathrm{~mol}$ ) the conversion of the alcohol is reduced (Table 5).

The most selective formation of 3-methylpyridine with up to $40 \%$ yield is possible at the minimum formaldehyde content (the ratio ethanol/formaldehyde/ammonia equals $1 / 0.39 / 1.5)$. As the formaldehyde content increases (1.0/ $1.07 / 1.5)$, the selectivity of pyridine formation increases from 33 to $50 \%$, and the selectivity of dimethylpyridine formation decreases from 14 to $5 \%$.

The revealed dependence of the higher methylpyridine yield on the lower amount of formaldehyde in the raw feed is associated with the reaction mechanism proposed in the publications [25, 31]. The main stages of the reaction between ethanol, formaldehyde, and ammonia could be illustrated by the following scheme (see Scheme 2):

It is supposed that imine is the initial product of the reaction; it is formed as a result of the interaction of ammonia with ethanol and acetaldehyde. The latter in its turn is a product of the reaction between alcohol and formaldehyde. The condensation of the formed imine and formaldehyde followed by the cyclization and aromatization result in the formation of pyridine. The condensation of imine without formaldehyde gives methylpyridines.

\section{Conclusion}

Thus, the study of the catalytic properties of different zeolites in the multi-component reaction of ethanol with formaldehyde and ammonia has established H-Beta zeolite to be the most active in the synthesis of pyridines; the
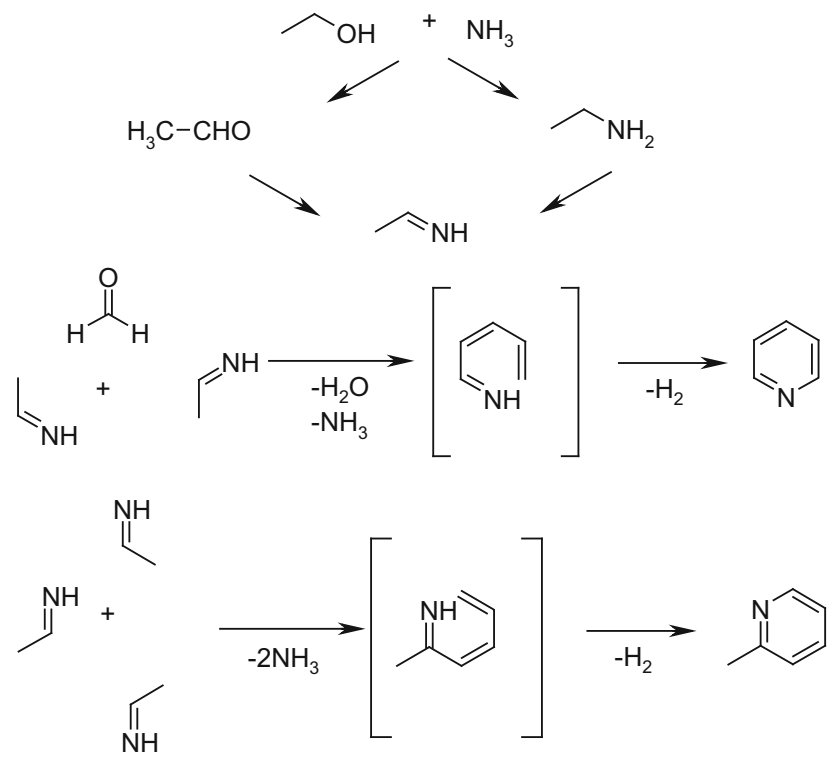

Scheme 2 Possible reaction mechanism for the formation of pyridine and picolines conversion of ethanol on it reaches $70 \%$ (at $400{ }^{\circ} \mathrm{C}$ and $2 \mathrm{~h}^{-1}$ ).

The high catalytic activity of H-Beta zeolite is stipulated both by the presence of a significant number of "strong" acid sites in it and by the specifics of the framework structure that provides free access of the reagents to the active sites of the catalyst.

Increasing the temperature from 200 to $400{ }^{\circ} \mathrm{C}$, the decrease in the volume flow rate from 10 to $0.5 \mathrm{~h}^{-1}$, and an increase in the formaldehyde content in the raw feed have been found to increase the conversion of ethanol on H-Beta zeolite.

The selectivity of the pyridine formation reaches its maximum of $49 \%$ at $200{ }^{\circ} \mathrm{C}$ and $2 \mathrm{~h}^{-1}$. The elevation of temperature, the reduced volume flow rate and formaldehyde concentration in the raw mix result in a higher quantity of methylpyridines and "heavy" compounds in the reaction product composition.

Acknowledgments The work was supported by Russian Foundation for Basic Research RFBR Project 14-03-97021-r_povolgie_a.

Open Access This article is distributed under the terms of the Creative Commons Attribution License which permits any use, distribution, and reproduction in any medium, provided the original author(s) and the source are credited.

\section{References}

1. Golunski SE, Jacson D (1986) Heterogeneous conversion of acyclic compounds to pyridine bases-a review. Appl Catal 23:1

2. Henry GD (2004) De novo synthesis of substituted pyridines. Tetrahedron Lett 60:6043

3. Scriven EFV, Toomey JE, Murugan R (1996) In Kirk-Othmer Encyclopedia of Chemical Technology, Pyridine and pyridine derivatives. In: Kroschwitz JI, Howe-Grant M (eds), 20. Wiley, New York, pp 641

4. Higasio YS, Shoji T (2001) Heterocyclic compounds such as pyrroles, pyridines, pyrollidins, piperdines, indoles, imidazol and pyrazins. Appl Catal 221:197-207

5. Lozbin VI, Mochalnikov SV, Solodov GA (2007) Production of the targeted market products by deep processing of coal-tar fractions. Proc TPU 2:149

6. Reddy Suresh Kumar K, Srinivasakannan C, Raghavan KV (2012) Catalytic vapor phase pyridine synthesis: a process review. Catal Surv Asia 16:28-35

7. Goe GI, Davis RD (1996) Really industries Ind. EP 0424466 B1. http://www.google.com/patents

8. Goe GI, Davis RD (1993) Really industries Ind. US 5,218,122. http://www.google.com/patents

9. McAteer CH, Brown DC, Davis RD (2002) Really industries Ind. EP 0837849 B1. http://www.google.com/patents

10. McAteer CH, Brown DC, Davis RD (1998) Really industries Ind. US 5,780,635. http://www.google.com/patents

11. Shimizu S, Abe N, Doba M (1989) Koei Chemical Co. JP 4,810,794. http://www.google.com/patents

12. Shimizu S, Abe N, Doba M (1996) Koei Chemical Co. EP 0382 543 B1. http://www.google.com/patents 
13. Shimizu S, Abe N, Doba M (1993) Koei Chemical Co. JP 5,237,068. http://www.google.com/patents

14. Shimizu S, Abe N, Doba M (2006) Koei Chemical Co. EP 1167352 B1. http://www.google.com/patents

15. Iwamoto K, Shoji T, Nakaishi Y (2001) Koei Chemical Co. US 6, 281,362 B1. http://www.google.com/patents

16. Suresh Kumar Reddy K, Sreedhar I, Raghavan KV (2008) Interrelationship of process parameters in vapor phase pyridine synthesis. Appl Catal A 339:15-20

17. Suresh Kumar Reddy K, Raghavan Inkollu Sreedhar Kondapuram Vijaya (2008) Behavior of a deactivating HZSM-5 with varying $\mathrm{Al}+3$ content in vapor phase Aminocyclization. Catal Lett 125:110-115

18. Suresh Kumar Reddy K, Sreedhar I, Raghavan KV (2011) Kinetic studies on vapor phase pyridine synthesis and catalyst regeneration studies. Can J Chem Eng 89:854-863

19. Adams CR, Falbe F (1986) Brennst Chem 47:184

20. Sato H, Shimizu S, Abe N, Hirose H (1994) Stud Surf Sci Catal 84:1951

21. Shimizu S, Abe N, Dohba M, Sato H, Hirose K (1998) Synthesis of pyridine bases on zeolite catalyst. Micro Meso Mater 21:447-451

22. Liu Y, Yang H, Zhang F, Ji Y, Li Y (2008) Synthesis of pyridine and picoline over Co-modified HZSM-5 catalyst. Chem Eng J $136: 282-287$
23. Rama Rao AV, Kulkarni SJ, Ramachandra Rao R, Subrahmanyanm M (1994) Synthesis of 2-picoline from acetone over modified ZSM-5 catalysts. Appl Catal 111:101-108

24. Van der Gaag FJ, Louter F, Oudejans JC, van Bekkum H (1986) Reaction of ethanol and ammonia to pyridines over zeolite ZSM5. Appl Catal 26:191-201

25. Kulkarni SJ, Ramachandra Rao R, Subrahmanyanm M, Rama Rao AV (1994) Synthesis of pyridine and picolines from ethanol over modified ZSM-5 catalysts. Appl Catal 113:1-7

26. Khazipova AN, Kutepov BI, Pavlov ML, Grigorieva NG, Pashkina AN. Travkin EA, Shestopal YL (2007) Synthesis of HNa-forms of high modular faujasites. J Appl Chem 80:1815-1818

27. Yushchenko VV (1997) Calculations of the zeolite acidity spectra using the ammonia thermal programmed desorption data. J Phys Chem 71:628

28. Plachenov TG, Kolosentsev SD (1988) Porosimetry (M: Chemistry): 175

29. Keltsev NV (1975) In fundamentals of the adsorption engineering (M: Chemistry):471

30. Baerlocher CH, McCusker LB, Olson DH (2007) In Atlas of zeolite framework types, $6^{\text {th }}$ edn. Elsevier, Amsterdam

31. Krishna Mohan VV, Narender N (2012) Synthesis of N-heterocyclic compounds over zeolite molecular sieve catalysts: an approach towards green chemistry. Catal Sci Technol 2:471-487 